\title{
Polymorphonuclear Neutrophil Elastase Measurement
}

National Cancer Institute

\section{Source}

National Cancer Institute. Polymorphonuclear Neutrophil Elastase Measurement. NCI

Thesaurus. Code C82027.

The determination of the amount of polymorphonuclear neutrophil elastase present in a sample. 